\title{
Corrupción y Derecho internacional de los derechos humanos
}

\author{
JOSÉ A. BURNEO LABRÍN*
}

La posesión del poder daña inevitablemente el libre juicio de la razón.

Immanuel Kant, Sobre la paz perpetua (1795)

\begin{abstract}
SUMARIO: I. LOS TRATADOS CONTRA LA CORRUPCIÓN.- 1. LA NOCIÓN DE CORRUPCIÓN Y LA ADECUACIÓN NORMATIVA E INSTITUCIONAL DE LOS ESTADOS PARTE.- 2. EL PAPEL DE LA COMUNIDAD INTERNACIONAL Y SU RELACIÓN CON LOS ESTADOS PARTE.- 3. LA RELACIÓN CON LOS DERECHOS HUMANOS SEGÚN LOS TRATADOS SOBRE CORRUPCIÓN.- II. LA LUCHA CONTRA LA CORRUPCIÓN FORMA PARTE INTEGRANTE DEL NUEVO ORDEN PÚBLICO INTERNACIONAL BASADO EN LA CARTA DE LAS NACIONES UNIDAS.- III. ¿CONSTITUYE LA CORRUPCIÓN UNA VIOLACIÓN DE LOS DERECHOS HUMANOS?
\end{abstract}

\section{INTRODUCCIÓN}

Uno de los hechos notables ocurridos en el transcurso de la última década del siglo XX, además del fin de la Guerra Fría y de la creación de la Corte Penal Internacional, es lo que podríamos calificar como el fin de la época de oro de la corrupción, particularmente a escala internacional. Como veremos luego, asistimos a una nueva época en este campo: la de la internacionalización de la lucha contra la corrupción y la necesaria gestación y desarrollo de sistemas internacionales de prevención y lucha contra la corrupción.

En efecto, recién en 1996 se adoptó, en el marco de la Organización de Estados Americanos, la primera Convención Internacional contra la Corrupción; en 1997, a escala interregional, en el marco de la Organización de Cooperación y de Desarrollo Económico (OCDE), la primera Convención de Lucha contra la Corrupción de Agentes Públicos Extranjeros en las Transacciones Comerciales Internacionales; en 1999, la primera convención europea al respecto, intitulada Convención Penal sobre la Corrupción; y, finalmente, a nivel mundial, en el marco de las Naciones Unidas, la tan esperada e importante Convención contra la Corrupción de 2003. Durante ese mismo año se adoptó, en

\footnotetext{
* El autor es abogado por la Pontificia Universidad Católica del Perú y cursó un postgrado (D.E.A.) en el Institut des Droits de I'homme de I'Université Catholique de Lyon, en Francia. Es doctor en Derecho por la Universidad Católica de Lovaina, LLN, de Bélgica. Enseña los cursos de Derechos Humanos y de Derecho Penal Internacional en la Facultad de Derecho de la PUCP.
} 
el marco de la Unión Africana, la Convención sobre la Prevención y la Lucha contra la Corrupción. Debe mencionarse que existen numerosos acuerdos internacionales realizados a partir de entonces en diversas instituciones internacionales intergubernamentales y regiones del mundo, incluida Asia.

Los tratados y acuerdos internacionales contra la corrupción expresan una radical e importante novedad en Derecho internacional. Por primera vez en la historia, la prevención de la corrupción y la lucha contra ella no son más dos asuntos que competen exclusivamente a los Estados. Como en otros campos, la comunidad internacional está interesada en llevar al cabo ambas acciones, con el fin de coadyuvar en algo que había sido antes de dominio exclusivo de los Estados. Estos cambios, de alguna manera, son tributarios y no hubieran sido posibles sin la institución, después de 1945 y sobre la base de la Carta de las Naciones Unidas, de un nuevo orden público internacional. Este nuevo orden, hasta hoy en día, aunque no sin ambigüedades vigentes, entre otros elementos constitutivos, otorga cierta entidad jurídica a la comunidad internacional y reformula los conceptos de dominio reservado y la soberanía de los Estados en su acepción clásica ${ }^{1}$.

La internacionalización de la lucha contra la corrupción, que de manera vertiginosa se está desarrollando a nivel regional, interregional y mundial, ocasiona indudables efectos sobre todos los países, particularmente sobre aquellos en los que las prácticas corruptas se habían institucionalizado y habían generado una especie de costumbre o de subcultura que comprometía - y compromete- a diversos sectores económicos, sociales y políticos que consideraban como natural y necesarias dichas prácticas. Pero también tendrá efectos sobre aquellos otros países en los que la corrupción, si bien se había proscrito internamente, pareciera tener raíces tan profundas que se torna virtualmente imposible de erradicar; o porque posee, como la Hidra de la mitología griega, una capacidad de autorregeneración tal que, como advertía Kant, es parte de ese mal que anida en el ser humano mismo ${ }^{2}$. La internacionalización en cuestión tendrá efectos, finalmente, en ciertos países conocidos como «desarrollados», en los que se aceptaba la corrupción hacia «afuera», con lo cual se instauraba una moral internacionalmente perversa que a la larga repercutía en la cultura y en los valores de toda la comunidad internacional. Es sabido, así, que no hace dos décadas, como se ha recordado en otras intervenciones, ciertos países «desarrollados» no penalizaban de jure o de facto la corrupción de funcionarios o agentes extranjeros porque la consideraban algo así como un mal necesario para tener éxito en los negocios que realizaban con los gobiernos de países llamados «en

1 Sobre la reformulación de la noción de soberanía de los Estados, véase el sugerente texto de FERRAJOLI, L. «La soberanía en el mundo moderno». En Derechos y garantías. La ley del más débil. Madrid: Trotta, 1999, pp. 125-158.

2 KANT, I. Sobre la paz perpetua. Madrid: Alianza Editorial, 2001 [1795], p. 60. 
desarrollo». De este modo, puede decirse que ningún país del mundo está libre de corrupción ${ }^{3}$.

A los efectos del presente trabajo, consideramos pertinente preguntarnos cuál es la relación, en el marco de los tratados contra la corrupción y sobre derechos humanos, respectivamente, entre corrupción y derechos humanos. En este orden de ideas, analizaremos primero los tratados anticorrupción mencionados antes, a fin de establecer la noción de corrupción, así como la de derechos humanos que en ellos podrían encontrase. En segundo lugar, nuestro esquema pretende esbozar algunas ideas sobre la relación existente entre, de una parte, la lucha internacional contra la corrupción con, de otra parte, la promoción y la defensa de los derechos humanos como elementos del orden público internacional que inaugura la Carta de las Naciones Unidas. En tercer lugar, analizaremos la relación específica posible entre la lucha contra la corrupción y los derechos humanos. Finalmente, presentaremos algunas observaciones o reflexiones generales a modo de conclusiones provisionales. Valga la aclaración metodológica de que nuestro enfoque se realiza desde el Derecho internacional.

\section{LOS TRATADOS CONTRA LA CORRUPCIÓN}

\section{La noción de corrupción y la adecuación normativa e institucional de los Estados parte}

Los tratados en vigor contra la corrupción de la OEA, la OCDE, el Consejo de Europa, la Unión Africana y las Naciones Unidas, antes mencionados, no presentan una definición comprehensiva de lo que se entiende o debe entenderse por corrupción. Empero, sí es posible afirmar que existe un consenso para calificar como corruptas ciertas prácticas políticas, sociales o comerciales, sean estas imputables a funcionarios (agentes públicos) o a particulares ${ }^{4}$.

Los tipos penales comunes que los tratados desarrollan constituyen una de las piezas esenciales en los que bien pueden denominarse «sistemas internacionales de prevención y de lucha contra la corrupción», toda vez que los hacen posibles. Es decir, dichos sistemas no podrían existir sin consensos internacionales sobre el contenido de ciertos tipos penales relativos a la corrupción. Entre los tipos así delineados podemos mencionar5:

3 El Rapport explicatif de la Convención Penal sobre la Corrupción (1999) del Consejo de Europa afirma: «Los países de Europa occidental, central y oriental, han sido literalmente sacudidos por los escándalos de corrupción a gran escala [...]” (párrafo 4). Traducción libre del autor a partir de la versión original en francés.

4 Consejo de Europa. Rapport explicatif de la Convención Penal sobre la Corrupción 1999, párrafo 3.

5 CapítulollldelaConvención delas NacionesUnidas, intituladoPenalizacióny Aplicación delaLey, artículos 15 a 42. 
1. soborno, o corrupción, activo y pasivo de funcionarios públicos nacionales, extranjeros e internacionales, así como en el sector privado;

2. malversación o peculado de bienes públicos o en el sector privado;

3. tráfico de influencias;

4. abuso de funciones;

5. enriquecimiento ilícito;

6. soborno;

7. blanqueo del producto del delito;

8. encubrimiento y obstrucción de la justicia;

9. responsabilidad de las personas jurídicas — pueden ser de carácter penal, civil o administrativa-; y,

10. participación y tentativa.

Además, las convenciones regulan aspectos relativos a la prescripción (artículo 29), al debido proceso (artículo 30), al embargo preventivo, a la incautación y al decomiso de bienes o activos (artículo 31), al secreto bancario (artículo 40) y a la recuperación de activos (artículo 51 y siguientes), a la protección de testigos (artículos 32 y 33), a la aplicación extraterritorial de la ley penal de los Estados (artículos 42 y 43), a la jurisdicción universal ${ }^{6}$ - aplicación de la regla aut dedere aut judicare en los casos de extradición-, a la cooperación internacional, a la extradición y a la asistencia judicial (artículos 43 a 50).

Como es habitual en los tratados internacionales, las convenciones establecen que los Estados parte deberán adecuar su normatividad jurídica e institucionalidad en general a fin cumplir con las obligaciones que han contraído.

\section{El papel de la comunidad internacional y su relación con los Estados parte}

El segundo de los aspectos a relevar, como parte esencial de la internacionalización de la lucha contra la corrupción, es el papel de la comunidad internacional y la relación que se establece con los Estados parte. Estos, en general, quedan obligados a producir informes periódicos sobre el cumplimiento de las obligaciones contraídas en virtud del tratado. Estos informes serán evaluados por los mecanismos que, también en virtud del

6 Lajurisdicción universalsobrelacorrupciónestablecidaenlaConvención delas Nacioneses denaturaleza facultativa a la vez que supletoria, y se ejercitará por el Estado requerido cuando no otorga la extradición que se le ha solicitado; el artículo 42, en su numeral 4, reza como sigue: «Cada Estado Parte podrá también adoptarlasmedidasnecesariasparaestablecersujurisdicciónrespectodelosdelitostipificadosconarreglo alapresenteConvencióncuandoelpresuntodelincuenteseencuentreen suterritorioyelEstadoPartenolo extradite". 
tratado, se han creado o se generan. Tales mecanismos, de otro lado, formularán recomendaciones para mejorar la aplicación de la convención.

\section{La relación con los derechos humanos según los trata- dos sobre corrupción}

Uno de los aspectos a remarcar es que los tratados sobre corrupción no establecen en su articulado, prima facie, relación directa alguna con los derechos humanos. Si revisamos el Tratado de las Naciones Unidas contra la Corrupción (2003), el término «derechos humanos» no aparece ni en su preámbulo ni en su extenso articulado. Algo semejante puede afirmarse respecto de la Convención Interamericana contra la Corrupción (1996), así como de la convención suscrita en el marco de la Organización para la Cooperación y el Desarrollo Económicos (1997). Una sola referencia se halla en el preámbulo de la Convención Penal sobre la Corrupción del Consejo de Europa (1999), en el sentido de que la corrupción, más que afectar directamente los derechos humanos, constituye una amenaza para la vigencia de la democracia y de dichos derechos ${ }^{7}$. La Convención de la Unión Africana para la Prevención y la Lucha contra la Corrupción (2003) presenta algunas referencias más claras tanto en su preámbulo como en su articulado ${ }^{8}$. Si bien los alcances de tales referencias no pueden ser analizados en esta intervención, parecieran coincidir en parte con la afirmación de que los actos de corrupción no constituyen una afectación directa sino un obstáculo para el disfrute de los derechos humanos, específicamente los denominados «derechos económicos, sociales y culturales» $\mathrm{O}$ «DESC».

Es pertinente señalar aquí que algo semejante sucede cuando se analizan los tratados de derechos humanos: a su vez, estos tampoco establecen relación alguna entre tales derechos y la lucha contra la corrupción. No aparece en ellos, de manera expresa ni implícita, referencia alguna a la corrupción.

Esta constatación no debe conducirnos a sostener que esta no referencia o no remisión expresa entre ambos tipos de tratados — salvo en los casos europeo y africano, en los términos arriba señalados - se deba a la nula o secundaria importancia de tal relación. Es preciso, más bien, realizar una relectura de ambos tipos de tratados para construir una interpretación más integral y sistemática que tenga en consideración ciertos elementos de conexión que no han sido, en esta etapa inicial de

7 «Soulignantque la corruption constitue una menace por la prééminence du droit, la démocratieet les droits del'homme».Préambule. Traducción libre: «Señalando que la corrupción constituye una amenaza para la vigencia del derecho, la democracia y los derechos humanos".

8 LaConvencióndelaUnión Africanaantescitada,luegodeseñalarensupreámbulolanecesidaddepromover y de proteger los derechos humanos y de los pueblos, en su artículo 2 establece como el cuarto objetivo: «Promover el desarrollo socio-económico mediante la eliminación de los obstáculos a la vigencia de los derechoseconómicos,sociales,culturales,civilesypolíticos»;ensuartículo3,fijacomounodesusprincipios que rigen a los Estados parte el «Respeto de los derechos humanos y de los pueblos conforme a la Carta africanadederechoshumanosydelospueblosyotrosinstrumentospertinentesqueconciernenlosderechos humanos». Traducción del autor a partir de la versión en francés.

CORRUPCIÓNY DERECHO

INTERNACIONAL DE LOS

DERECHOS HUMANOS 
la internacionalización de la lucha contra la corrupción, debidamente tenidos en consideración y puestos en relieve. Volveremos más adelante sobre esta temática.

\section{II.LA LUCHA CONTRA LA CORRUPCIÓN FORMA PARTE INTEGRANTEDELNUEVO ORDEN PÚBLICO INTERNACIONAL BASADO EN LA CARTA DE LAS NACIONES UNIDAS}

El Derecho de gentes clásico, ese que fuera tempranamente esbozado y definido por Francisco de Vitoria ${ }^{9}$ cuando la primera potencia mundial inició la mayor empresa de la historia moderna a inicios del siglo XVI, hubiera rechazado como elementos extraños y violatorios de la soberanía estatal el conjunto de medidas y mecanismos que encontramos a fines del siglo XX en los tratados contra la corrupción.

Ese Derecho de gentes clásico, sin embargo, luego de dos hecatombes mundiales, debió ceder el paso a un nuevo Derecho internacional, portador de nuevos conceptos, principios jurídicos, instituciones, y ética pública e internacional que conforman el nuevo Orden Público Internacional (OPI), que emergió con la Carta de las Naciones Unidas en $1945^{10}$.

Los elementos centrales del nuevo ordenamiento jurídico internacional, que serán fuertemente sostenidos y desarrollados desde entonces por una siempre creciente cantidad de instrumentos internacionales, instituciones y normas jurídicas internacionales convencionales y no convencionales, pueden ser sintetizados en las siguientes proposiciones ${ }^{11}$ :

1. la paz y la seguridad de la humanidad son bienes jurídicos que atañen a la comunidad internacional, representada centralmente por la Organización de las Naciones Unidas y, de acuerdo con su carta, por las entidades regionales;

2. la soberanía de los Estados se redefine y reformula de modo tal que, a nivel internacional, desaparece el jus ad bellum ilimitado que conduce a la guerra de agresión;

3. la soberanía de los Estados se redefine y reformula de modo tal que, en su misma esfera interna, la manera como trate a los seres humanos bajo su jurisdicción no es más, bajo ciertas condiciones, un asunto de su dominio reservado, sino que podrá y deberá ser supervisado e incluso intervenido por la comunidad internacional;

9 ConsúlteseDeVıтoRıA,Francisco. «Deindis».En Doctrinasobrelosindios.Salamanca:EditorialSan Esteban, 1989 [1539].

10 Enestepunto,nosinspiramosapartirdeltextodelprofesorF.RigauxdelaUniversidaddeLovaina,enelque exponesobre «L'ordrejuridiquedu 'cercleenchanté'(Charmedcircle)desnationschrétiennes».Consúltese Rıgaux,Francois. «Lanotiond'ordremondial(etd'unnouvelordremondial)». En Mondialisation, mutationsde sociétés et enjeux de justice. Bruselas: Commission Justice et Paix asbl, 1999, pp. 40 y 41.

11 Sobre los elementos constitucionales del nuevo Orden Público Internacional, véase CARriLlo S., Juan A. Soberanía de los estados y derechos humanos en Derecho internacional contemporáneo. Madrid: Tecnos, 2001. 
4. los seres humanos, sin excepción alguna, tienen iguales derechos reconocidos y protegidos por normas jurídicas internacionales, y algunos de tales derechos son de carácter inderogable en todo tiempo y lugar;

5. los pueblos tienen todos iguales derechos, esto es, el derecho a la libre determinación, a proveer a su desarrollo económico, social y cultural, a los medios de subsistencia, y a sus riquezas y recursos naturales;

6. la comunidad internacional pone en marcha la cooperación internacional con el objeto de resolver problemas internacionales de orden económico, social, intelectual y humanitario, y a fin de asegurar la paz y el bienestar de la humanidad;

7. la violación de ciertas normas básicas del nuevo OPI constituye un crimen internacional susceptible de ser perseguido por separado (jurisdicción universal) o en conjunto (jurisdicción internacional) por los Estados, de acuerdo con normas convencionales pero también no convencionales que se imponen a los Estados; y,

8. todo individuo, cualquiera que sea su función en el Estado y en la sociedad, es justiciable por la comisión de crímenes internacionales, y desaparecen o se reformulan las nociones de inmunidad internacional y del acto de Estado, además de no aceptarse la impunidad en relación con tales ilícitos internacionales.

Si examinamos los mecanismos previstos en los tratados contra la corrupción, encontraremos algunos elementos vinculados orgánicamente a las proposiciones arriba indicadas. En síntesis, tales mecanismos son la manifestación de la nueva concepción de soberanía del Estado y del papel de la comunidad internacional, en cuanto, de una parte, aquel cede, en este caso en virtud de normas convencionales, ciertos aspectos antes exclusivos de su jurisdicción interna y, de otra parte, acepta ser fiscalizado y hasta requerido externamente sobre la manera como cumple las obligaciones convencionalmente adquiridas. Así, de acuerdo con los tratados contra la corrupción, el Estado parte:

1. deberá sancionar internamente los tipos penales convenidos;

2. acepta, bajo ciertas condiciones, la extraterritorialidad de las leyes penales de los otros Estados parte;

3. acepta el ejercicio de la jurisdicción universal por los otros Estados parte;

4. deberá aplicar, en general, la regla aut dedere aut judicare en todos los casos de extradición previstos en los tratados;

5. deberá informar al mecanismo previsto o generado por el tratado respecto de la manera como dan cumplimiento a sus obligaciones convencionales; y, 
6. acepta la fiscalización, esto es, la injerencia de los mecanismos precitados.

Encontramos los mecanismos mencionados de manera especial en otro tipo de tratados, los que conforman el Derecho internacional de los derechos humanos, tanto a nivel universal como regional, y conforman así los sistemas internacionales de protección de los derechos humanos. Ello nos lleva a concluir que la internacionalización de la prevención y la lucha contra la corrupción están generando también la gestación y el funcionamiento - aunque incipiente todavía a nivel regional y universal - de sistemas internacionales de prevención y lucha contra la corrupción.

La utilización de mecanismos como los antes señalados, empero, no basta para concluir que la prevención y la lucha contra la corrupción forman parte de las reglas constitutivas del OPI post 1945. Sobre todo porque, al analizar todos los tratados regionales, interregionales y universales antes citados, es posible constatar que ellos no efectúan referencia alguna a la Carta de las Naciones Unidas ni a las cartas regionales correspondientes. En otros términos, no se encuentra una mención expresa en el sentido de que los actos de corrupción penalizados constituyen actos contrarios a las cartas internacionales, ni de que la prevención y la lucha contra la corrupción tienen sustento definitivo en ellas. Esta ausencia debe destacarse tanto más si se constata que sucede todo lo contrario en los tratados de derechos humanos: esto es, se afirma que las normas jurídicas internacionales relativas a estos son parte de los principios enunciados en las cartas internacionales correspondientes, así como que las violaciones de tales derechos constituyen una violación de aquellas. Así, por ejemplo:

- «Considerando que, conforme a los principios enunciados en la Carta de las Naciones Unidas, la libertad, la justicia y la paz en el mundo tienen por base el reconocimiento de la dignidad inherente a todos los miembros de la familia humana y de sus derechos iguales e inalienables ${ }^{12}$;

- «Considerando que la Carta de las Naciones Unidas impone a los Estados la obligación de promover el respeto universal y efectivo de los derechos humanos y libertades» ${ }^{13}$;

- «Considerando la obligación que incumbe a los Estados en virtud de la Carta, en particular del Artículo 55, de promover el respeto universal y la observancia de los derechos humanos y las libertades fundamentales» ${ }^{14} ; \mathrm{y}$, 
- «Reafirmando que todo acto de tortura u otros tratos o penas crueles, inhumanos o degradantes constituyen una ofensa a la dignidad humana y una negación de los principios consagrados en la Carta de la Organización de los Estados Americanos y en la Carta de las Naciones Unidas y son violatorios de los derechos humanos y libertades fundamentales proclamados en la Declaración Americana de los Derechos y Deberes del Hombre y en la Declaración Universal de los Derechos Humanos» ${ }^{15}$.

Podría esbozarse la hipótesis de que, pese a la no remisión ni conexión establecida en los tratados correspondientes, la prevención y la lucha contra la corrupción dimanan orgánicamente de la Carta de las Naciones Unidas y de las cartas regionales, y de que los actos de corrupción son contrarios a los principios y fines de aquellas.

Un análisis prima facie de la Carta de las Naciones Unidas nos permite relevar lo siguiente:

- la organización se declara resuelta a «crear condiciones bajo las cuales puedan mantenerse la justicia» y «promover el progreso social y a elevar el nivel de vida dentro de un concepto más amplio de libertad $\gg^{16}$;

- el artículo 1 establece, entre los «propósitos» de la organización, «3. Realizar la cooperación internacional en la solución de problemas internacionales de carácter económico, social, cultural o humanitario», así como «4. Servir de centro que armonice los esfuerzos de las naciones por alcanzar estos propósitos comunes»;

- la organización promoverá, de acuerdo con el artículo 55, «a. niveles de vida más elevados, trabajo permanente para todos y condiciones de progreso y desarrollo económico y social», y también «b. La solución de problemas internacionales de carácter económico, social y sanitario, y de otros problemas conexos, y la cooperación internacional en el orden cultural y educativo»; y,

- Los Estados, sin excepción alguna, según el artículo 56, «se comprometen a tomar medidas conjunta o separadamente, en cooperación con la Organización, para la realización de los propósitos consignados en el artículo 55».

A la luz de los textos estatutarios precitados, forman parte de los principios constitutivos de las Naciones Unidas: (a) la promoción del desarrollo y el progreso económico, social, cultural, así como elevar el nivel de vida, etcétera; (b) realizar la cooperación internacional para eliminar los obstáculos o problemas para alcanzar lo anterior; y (c) la obligación de los Estados de adoptar medidas separadas o conjuntamente para realizar los propósitos anteriores.

CORRUPCIÓNY

DERECHO

INTERNACIONAL

DE LOS

DERECHOS

HUMANOS 
El análisis de la Carta de la Organización de los Estados Americanos nos permite sostener conclusiones semejantes a las que se desprenden de la Carta de las Naciones Unidas, si adicionalmente se hace hincapié en que entre sus propósitos esenciales se encuentra también «Promover y consolidar la democracia representativa» (artículo 2b), así como «Promover [... el] desarrollo económico, social y cultural» (artículo 2f), y que se ha incorporado un capítulo VII titulado «Desarrollo integral» (artículos 30 a 52) en los que se incluyen diversos aspectos relativos, por ejemplo, a los derechos económicos, sociales y culturales.

Lo hasta aquí esbozado nos permite, entonces, realizar dos conclusiones que son como las dos caras de una misma moneda. En primer lugar, los actos graves de corrupción son actos contrarios a los fines y propósitos recogidos en la Carta de las Naciones Unidas y en otras cartas regionales. En segundo lugar, la prevención y la lucha contra la corrupción están indisolublemente vinculadas con los principios y propósitos esenciales de la Carta de las Naciones Unidas y de la Organización de Estados Americanos, así como seguramente de las otras organizaciones regionales. En efecto, la corrupción, de acuerdo con lo que unánimemente afirman los Estados en los tratados correspondientes y en la literatura especializada ${ }^{17}$, es un obstáculo al desarrollo integral de los pueblos, un factor contrario a la democracia, a la justicia, y al imperio de la ley, cuya gravedad y envergadura requieren de la intervención de la comunidad internacional así como de la acción separada y conjunta de los Estados que la conforman. Expresamente, se ha afirmado que la «gravedad de los problemas y las amenazas que plantea la corrupción para la estabilidad y seguridad de las sociedades al socavar las instituciones y los valores de la democracia» es tal que «la corrupción ha dejado de ser un problema local para convertirse en un fenómeno transnacional que afecta a todas las sociedades y economías» ${ }^{18}$. De aquí se sigue que la corrupción es contraria a $-\mathrm{y}$ constituye una negación de- los fines y propósitos de la Carta de las Naciones Unidas y de la Organización de los Estados Americanos - así como seguramente de las correspondientes a Europa y a la Unión Africana-, según analizamos antes. En consecuencia, existe un legítimo interés en que la comunidad internacional, conforme a las referidas cartas internacionales, instaure sistemas internacionales de prevención y de lucha contra la corrupción a escala universal y regional. En palabras de las Naciones Unidas, «[es] esencial la cooperación internacional para prevenir y luchar contra ella» ${ }^{19}$. De este modo, es posible sostener que las medidas de prevención y de lucha contra la corrupción forman parte de los principios y valores del Orden Público Internacional contemporáneo.

17 Entre la abundante literatura especializada, merece destacarse la obra colectiva editada en nuestro país y compilada por Óscar Ugarteche, Vicios públicos. Poder y corrupción. Lima: Fondo de Cultura Económica y Sur, 2005.

18 Convención de las Naciones Unidas, 2003. Preámbulo. 
La afirmación precedente acarrea consecuencias en el Derecho internacional. Veamos por qué. De acuerdo con los tratados sobre corrupción, los actos descritos como constitutivos de esta serían únicamente infracciones al orden público de los Estados y serán eventualmente delitos únicamente si así lo establece el Derecho penal de los Estados. A este efecto, los Estados, en virtud de los tratados de los que son parte, se comprometen a incorporar en sus respectivos códigos penales los tipos penales establecidos convencionalmente. Realizada esta adecuación legislativa, el sistema internacional contra la corrupción —esto es, la cooperación y la asistencia judicial, la aplicación extraterritorial de la ley penal, incluida la jurisdicción universal, y la aplicación de la regla aut dedere aut judicare en los casos de extradición- puede funcionar. Este sistema internacional es de base convencional. Un sistema análogo existe en materia de derechos humanos ${ }^{20}$.

Ahora bien, en la medida que la corrupción afecta o amenaza bienes jurídicos protegidos internacionalmente por la Carta de las Naciones Unidas y las cartas regionales, es congruente concluir que, en el futuro y en cuanto se consoliden los sistemas actualmente en desarrollo, la prevención y la lucha contra la corrupción se realice en virtud de las cartas mencionadas y no solo en virtud de los tratados correspondientes. En este caso, nos encontraríamos ante un sistema internacional de base extraconvencional $y$, en consecuencia, la comunidad internacional, a través de los sistemas internacionales de prevención y de lucha contra la corrupción extraconvencional, actuaría en los casos más graves y flagrantes, de manera análoga a la manera en que funcionan los sistemas internacionales de protección de los derechos humanos extraconvencionales ${ }^{21}$.

Y si en la actualidad la persecución penal se realiza únicamente en virtud de normas penales convencionales, en el futuro podría realizarse, en la medida en que así lo reconozcan los Estados, en virtud de normas consuetudinarias. Seguramente hoy en día sería prematuro afirmar la existencia de normas internacionales consuetudinarias relativas a los tipos penales contenidos en los tratados contra la corrupción. Pero en el

20 Sobreel sistema internacional de protección de los derechos humanos, respecto de las Naciones Unidas, véase ViLlán D., Carlos. Curso de Derecho internacional de los derechos humanos. Madrid: Trotta, 2006; y, respecto de nuestro hemisferio, véase FAúNDEZ L., Héctor. El sistema interamericano de protección de los derechos humanos. Aspectos institucionales y procesales. San José de Costa Rica: IIDH, 2004.

21 Los derechos humanos son protegidos, en el marco de las Naciones Unidas y de la Organización de EstadosAmericanos, mediantedostiposdesistemas, unodenominado «convencional»yotrodenominado «extraconvencional». Elprimerosebasaenlostratados;elsegundo,enlaDeclaraciónUniversaldeDerechos Humanos, en el caso de la ONU, y en la Declaración Americana de Derechos y Deberes del Hombre, en el de la OEA. La existencia de los derechos humanos, de forma autónoma respecto de los tratados, acarrea unaconsecuencia:todoslosEstadostienenlaobligacióndepromoverlosyrespetarlosactuandoseparadao conjuntamente. Lacomunidadinternacionaltiene,entonces, lapotestaddefiscalizarydepedircuentasatodos losEstadosrespectodelavigenciadelos derechoshumanosensusrespectivosterritorios. Estaexistencia reforzada ha dado lugar al surgimiento post 1945 de los dos mencionados sistemas complementarios de protecciónenelsenode las Naciones Unidas: el «extraconvencional» yel «convencional». Algosemejante sucedea nivel regional interamericano. Entreambos sistemas «onusianos" se promueven y fiscalizan los derechos humanos, los cuales incluyen, comoveremos más adelante, derechos amenazados o afectados poractos decorrupción. Porellonoes necesario,en unaprimeraaproximación que desdeaquírealizamos, quelossistemasinternacionales deprevencióny deluchacontralacorrupción incluyanelmonitoreodelos derechos afectados por esta. 
futuro, ciertos actos constitutivos de la corrupción podrían erigirse en delitos internacionales también sobre la base de normas consuetudinarias. En este caso, los tratados generarían normas jurídicas internacionales consuetudinarias de carácter penal, y darían lugar, bajo ciertas condiciones, al ejercicio de la jurisdicción universal por los Estados. Tal vez sea prematuro responder a la cuestión de saber si, en el futuro, podría otorgarse, respecto de los delitos más graves de corrupción, competencia a la Corte Penal Internacional, para lo cual habría que introducir las enmiendas correspondientes de acuerdo con el Estatuto de Roma que rige a esta Corte ${ }^{22}$.

\section{III. ¿CONSTITUYE LA CORRUPCIÓN UNA VIOLACIÓN DE LOS DERECHOS HUMANOS?}

De acuerdo con lo expuesto, en relación con los derechos humanos, cuya defensa, disfrute y promoción son parte esencial del Orden Público Internacional, es fundado igualmente concluir, en una primera afirmación, que la corrupción — concretada en diversos actos incriminados por los tratados- genera condiciones adversas y que supone un obstáculo y una amenaza a la vigencia de aquellos ${ }^{23}$. La vigencia de los derechos humanos requiere del funcionamiento pleno de la democracia, del desarrollo económico integral y sostenible, del imperio de la justicia y de una ética pública respetuosa de la dignidad e igualdad de los seres humanos y de los pueblos. El corolario es, entonces, que la prevención y la lucha contra la corrupción crearán condiciones favorables y facilitarán la realización de los derechos humanos.

Las afirmaciones contenidas en el párrafo precedente, sin embargo, no responden netamente a la cuestión planteada. En otros términos, ¿los actos de corrupción tipificados en los tratados respectivos, además de constituir obstáculos y una amenaza a la vigencia de los derechos humanos, constituyen actos violatorios de estos derechos? Es de tener muy en consideración que en ninguno de los tratados antes mencionados, según analizamos en la sección I precedentemente, se responde expresamente a la cuestión planteada, y que en la literatura que hemos revisado no hemos hallado tampoco una respuesta satisfactoria. Pretendemos aquí esbozar algunas ideas que permitan abordar adecuadamente esta materia.

22 Las violaciones más graves de los derechos humanos y otras infracciones graves al Orden Público Internacionalson perseguiblesenvirtuddenormaspenales internacionalesnoconvencionalesmedianteel mecanismodelajurisdicciónuniversal.Sonigualmenteperseguiblestalesviolacioneseinfraccionesenvirtud de tratados, comoes el caso de la tortura, o de los delitos previstos en el Estatuto de Roma que crea la Corte Penal Internacional.

23 «SeñalandoquelacorrupciónconstituyeunaamenazaparalavigenciadelEstadodederecho,lademocracia y los derechos humanos", leemos en el Preámbulo de la Convención Penal sobre la Corrupción (1999) del Consejo de Europa. (Traducción del autor a partir de la versión en francés). Véase también el artículo 2(4) de la Convención, 2003, de la Unión Africana sobre la Prevención y la Lucha contra la Corrupción. No encontramos referencias expresas, enelmismosentido,en la Convención de las Naciones Unidas de2003, ni tampoco en la Convención Interamericana de 1996. 
En primer término, es necesario precisar, en Derecho internacional, el contenido de los derechos humanos, sus sujetos titulares y, por ende, sus eventuales víctimas en caso de actos violatorios de sus derechos, así como los sujetos que incurren en responsabilidad internacional, sea en el marco del Derecho internacional de los derechos humanos o del Derecho penal internacional.

La Declaración Universal de Derechos Humanos (1948) enuncia derechos que ulteriormente se han calificado como Derechos Civiles y Políticos, y como Derechos Económicos, Sociales y Culturales en sendos pactos internacionales (PIDCP y PIDESC respectivamente), ambos de 1966. Por referirnos únicamente al ámbito de las Américas y el Caribe, la Declaración Americana de los Derechos y Deberes del Hombre (1948) enuncia también los dos tipos de derechos, que fueron luego recogidos en la Convención Americana sobre Derechos Humanos (1969) y en el protocolo adicional a esta convención en materia de derechos económicos, sociales y culturales (1988), denominado también Protocolo de San Salvador. De este modo, en Derecho internacional han quedado firmemente establecidos ambos tipos de derechos. A estos ya clásicos deberán añadirse el derecho al desarrollo y el derecho a un medio ambiente sano. Este último ha sido objeto de una mención especial en los artículos 12 y 11 del PIDESC y del Protocolo de San Salvador, respectivamente, así como en el Convenio 169 de la OIT (artículo 7.4).

En cuanto a los titulares de derechos, los individuos lo son de los derechos civiles y políticos así como de los derechos económicos, sociales y culturales, pero también deben mencionarse como titulares de derechos a ciertos sujetos colectivos. En efecto, los pactos internacionales de las Naciones Unidas hacen lugar en tanto sujetos a los individuos, pero también a sujetos colectivos, tales como los sindicatos ${ }^{24}$, las minorías ${ }^{25}$ y los pueblos ${ }^{26}$. De otro lado, el Convenio 169 de la OIT sobre Pueblos Indígenas y Tribales (1989) les reconoce un conjunto de derechos. De este modo, como titulares de derechos humanos tanto individuos como sujetos colectivos, al producirse hechos violatorios de sus derechos, tales sujetos individuales y/o colectivos estarán lógicamente habilitados para interponer las denuncias y acciones que la normatividad internacional les posibilite ante los organismos correspondientes. Sin embargo, será necesaria una detenida revisión del locus standi y jus standi de tales sujetos en Derecho internacional ${ }^{27}$. En cualquier caso, debe distinguirse

24 EI PIDESC, en su artículo 8(1), establece: «Los Estados partes en el presente Pacto se compromete a garantizar: [...]: b) El derecho de los sindicatos a formar federaciones [...]; c) El derecho de los sindicatos a funcionar sin obstáculos y sin otras limitaciones que las que prescriba la ley [...]".

25 EIPIDCP, en su artículo 27, hace referencia a las minorías, si bien vincula el derecho a las personas que las integran. Aniveleuropeo, véase el Convenio Marco parala Protección de las Minorías, en vigor desde 1988, con veintisiete Estados parte.

26 Elartículoprimero, comúnaIPIDESCyaIPIDCP,establece: «1.Todos los pueblostienenelderechodelibre determinación. Envirtuddeestederechoestablecenlibrementesucondición políticay proveenasimismoa su desarrollo económico, social y cultural».

27 EIProtocoloAdicional(1995)alaCartaSocialEuropea(1965)permitelainterposicióndedenunciasporparte de entidades colectivas ante el Comité Europeo de Derechos Sociales.

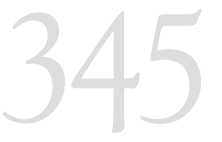

CORRUPCIÓN Y

DERECHO

INTERNACIONAL

DE LOS

DERECHOS

HUMANOS 
la calidad de víctima de la legitimación activa para intervenir ante los sistemas de protección internacional.

De todos modos, deberá identificarse con precisión la manera en que los tipos penales delineados en las convenciones contra la corrupción afectan los derechos protegidos por el Derecho internacional de los derechos humanos. Probada esta afectación, nos encontraríamos sin duda alguna frente a violaciones de los derechos humanos. Así, por ejemplo, la malversación de fondos destinados a prestar servicios de salud o de educación a un pueblo indígena — capítulos V y VI, respectivamente, del Convenio 169 de la OIT antes citada-, iconstituye un acto que afecta el derecho a la salud y a la educación del referido pueblo indígena? Los derechos a la justicia, al debido proceso y a la igualdad ante la ley que posee todo individuo, ise ven afectados cuando la autoridad judicial, como efecto del soborno que acepta de una de las partes, resuelve arbitrariamente?

El Derecho internacional de los derechos humanos, de otro lado, considera que en el plano nacional los particulares pueden afectar derechos fundamentales de los individuos o de lo sujetos colectivos titulares de derechos, y corresponde en tales eventualidades al Estado intervenir conforme a su propio ordenamiento jurídico para amparar el derecho y reparar a las eventuales víctimas. A nivel internacional, empero, los sistemas internacionales de derechos humanos solo atribuyen responsabilidad a los Estados, y los individuos, sin distinción alguna, son justiciables en los sistemas internacionales penales.

En el ámbito del Derecho penal internacional, bajo ciertas condiciones, en casos de muy especial gravedad, las violaciones de derechos humanos constituyen crímenes internacionales que caen bajo la competencia de la Corte Penal Internacional creada por el Estatuto de Roma (1998). Pero no toda violación de derechos humanos constituye un crimen internacional que pueda denominarse crimen de lesa humanidad: lo es solo aquella cuya gravedad, de acuerdo con los términos del Estatuto de Roma, reúne los requisitos de este gravísimo tipo penal. Del mismo modo, podría pensarse que no todo acto de corrupción podría constituir en el futuro un crimen internacional, sino solo aquel cuya gravedad especial merezca tal calificativo por la comunidad internacional.

\section{REFLEXIONES FINALES}

A continuación, presentamos algunas reflexiones finales a modo de conclusiones:

1. La internacionalización de la prevención y la lucha contra la corrupción constituye un fenómeno nuevo en las relaciones internacionales, y expresa una seria preocupación por parte de la 
comunidad internacional que ha sido plasmada positivamente en el Derecho internacional.

2. La corrupción, particularmente sus actos más graves, afecta el Orden Público Internacional contemporáneo, tal como ha sido sancionado en la Carta de las Naciones Unidas y en las cartas regionales; en consecuencia, la prevención y la lucha que los tratados contra la corrupción instituyen a escala internacional tienen fundamento último en las referidas cartas internacionales, y así debiera ser expresamente formulado en acuerdos e instrumentos internacionales.

3. La corrupción afecta y amenaza la vigencia de los derechos humanos. La prevención y la lucha que se llevan al cabo promueven la vigencia de tales derechos, y en tal sentido debiera igualmente hacerse mención en acuerdos e instrumentos internacionales.

4. Determinados actos de corrupción, si afectan directamente derechos protegidos por el Derecho internacional de los derechos humanos, constituyen una violación de los derechos humanos, ante lo cual pueden generarse reclamos internacionales, de estar así habilitadas (locus standi, jus standi) las víctimas individuales o colectivas que fueran titulares de los derechos afectados.

5. Asistimos a un proceso de gestación y desarrollo de sistemas internacionales de prevención y lucha contra la corrupción, similares a los existentes en el Derecho internacional de los derechos humanos, si bien no existe un sistema internacional extraconvencional, como sí existe actualmente en el Derecho internacional de los derechos humanos.

6. La persecución penal prevista en las convenciones contra la corrupción ha dado lugar a uno de los elementos centrales de la internacionalización de la lucha contra la corrupción, lo que se expresa en la aplicación extraterritorial de la ley penal de los Estados, de la regla aut dedere aut judicare a los efectos de la extradición, incluida la jurisdicción universal de base convencional.

7. Es prematuro afirmar la existencia de normas consuetudinarias internacionales relativas a la lucha anticorrupción; empero, los tratados contra la corrupción pueden dar lugar a la gestación de normas consuetudinarias internacionales a efectos de desarrollar acciones tanto de prevención como de fiscalización, tareas que actualmente se realizan únicamente en virtud de normas convencionales.

8. La categoría de crímenes internacionales, incluidos en la competencia material de la Corte Penal Internacional, comprende únicamente aquellos considerados especialmente graves por la comunidad internacional; de existir, en el futuro, consenso en el seno de dicha comunidad, ella podría incluir en esta categoría aquellas modalidades de corrupción especialmente graves. 